\title{
Intestinal Epithelial Cells Use Two Distinct Pathways for HLA Class II Antigen Processing
}

\author{
Robert M. Hershberg, ${ }^{\star \ddagger}$ Paul E. Framson, ${ }^{\star}$ Diane H. Cho, ${ }^{\star}$ Lawrence Y. Lee, ${ }^{\star}$ Susan Kovats, ${ }^{\ddagger}$ Jill Beitz, ${ }^{\S}$ Janice S. Blum, ${ }^{\S}$ \\ and Gerald T. Nepom*‡ \\ *Immunology and Diabetes Programs, Virginia Mason Research Center, Seattle, Washington 98101; ${ }^{\ddagger}$ Department of Immunology, \\ University of Washington School of Medicine, Seattle, Washington 98195; and ${ }^{\S}$ Department of Microbiology and Immunology, Indiana \\ University School of Medicine, Indianapolis, Indiana 46202
}

\begin{abstract}
Intestinal epithelial cells express a low level of HLA class II molecules constitutively, with elevated levels seen in the setting of mucosal inflammation including inflammatory bowel disease. The ability of intestinal epithelial cells to act as antigen presenting cells for $\alpha \beta \mathrm{CD}^{+} \mathrm{T}$ lymphocytes was examined through a molecular analysis of the HLA class II antigen processing pathway. We have shown that intestinal epithelial cells contain abundant constitutive levels of the cathepsin proteases proven to function in HLA class II mediated antigen presentation. Activation of these cells by $\gamma$-IFN induced the expression of invariant chain and HLA-DM $\alpha \beta$, thus facilitating the formation of compact, SDS-stable HLADR $\alpha \beta$ heterodimers. Using HLA-DR-restricted T cells and retroviral mediated gene transfer of HLA-DR alleles into the intestinal epithelial cell lines HT-29 and T84, we demonstrated efficient antigen processing and presentation to $\mathrm{CD4}^{+} \mathrm{T}$ lymphocytes in the presence of the proinflammatory cytokine $\gamma$-IFN. The class II processing pathway and presentation in the presence of $\gamma$-IFN was indistinguishable from that observed with a conventional antigen presenting cell. Antigen processing also occurred in intestinal epithelial cells in the absence of $\gamma$-IFN, and in contrast to that seen after stimulation with $\gamma$-IFN, required high concentration of antigen and was not inhibited by the protease inhibitor leupeptin. These data suggest the use of two distinct pathways of HLA class II antigen processing in enterocytes with differential immunomodulatory properties in the presence or absence of mucosal inflammation. (J. Clin. Invest. 1997. 100:204-215.) Key words: intestinal mucosa • inflammatory bowel disease $\cdot$ antigen presentation $\cdot \mathrm{T}$ lymphocytes • human
\end{abstract}

\section{Introduction}

The epithelium of the intestine is a single cell layer that separates the highest concentration of foreign antigen from the largest population of lymphocytes in the body. Numerous re-

Address correspondence to Robert M. Hershberg, M.D., Ph.D., Virginia Mason Research Center, 1000 Seneca Street, Seattle, WA 98101. Phone: 206-223-6391; FAX: 206-223-7543; E-mail: hersh@u.washing ton.edu

Received for publication 26 November 1996 and accepted in revised form 9 April 1997.

J. Clin. Invest.

(C) The American Society for Clinical Investigation, Inc.

0021-9738/97/07/0204/12 \$2.00

Volume 100, Number 1, July 1997, 204-215 ports have described the expression of a low level of HLA class II antigens on the surface of normal intestinal epithelial cells (IECs) ${ }^{1}(1)$ and have demonstrated that increased expression of these molecules is associated with a diverse group of pathological conditions including inflammatory bowel disease (IBD) (1), graft versus host disease (GVHD) (2) and celiac disease (3). Since the expression of HLA class II molecules is a prerequisite for cells that function as antigen presenting cells (APCs) to $\mathrm{CD}^{+} \mathrm{T}$ lymphocytes (for review see reference 4), these observations suggested that the intestinal epithelium might function in the initiation and/or regulation of $\mathrm{CD}^{+} \mathrm{T}$ cell responses in the mucosa of the intestinal tract. Importantly, mucosal $\mathrm{CD}^{+} \mathrm{T}$ cells are implicated in the pathogenesis of IBD (5) and are required for the establishment of oral tolerance (6-8).

Efficient processing and presentation of antigens to $\mathrm{CD}^{+}$ $T$ cells requires not only the expression of HLA class II molecules, but also the invariant chain (Ii), the HLA-DM $\alpha \beta$ heterodimer, and a series of proteases that facilitate partial proteolysis of both internalized antigen and class II biosynthetic intermediates (for review see references 9 and 10). In most cells with known APC function (e.g., B cells, macrophages, and dendritic cells), the expression of these molecules is coordinately regulated (11). The intestinal epithelium illustrates an interesting exception, where the expression of HLA class II molecules has been observed in the absence of Ii (12). In fact, some have speculated that the HLA class II molecules expressed constitutively on the gut epithelium may have a different function from those induced by mucosal inflammation (13). Several groups have described the presentation of antigens by IECs in human (14), rat (15), and mouse (16). However, no studies, to date, have provided a detailed molecular analysis of the HLA class II processing pathway in IECs to address potential differences in the structure and function of HLA class II molecules in these cells before and after cytokine stimulation.

Using well-characterized human IECs engineered to express constitutive class II molecules by retrovirus-mediated gene transfer, we have investigated the ability of IECs to both process and present peptide antigens to human $\mathrm{CD}^{+} \mathrm{T}$ lymphocytes in the presence or absence of $\gamma$-IFN. In the presence of $\gamma$-IFN, IECs used a conventional class II pathway that involves Ii and HLA-DM, was inhibited by leupeptin, and facilitated efficient antigen processing and presentation even at low

1. Abbreviations used in this paper: APC, antigen presenting cell; B-LCL, B lymphocyte cell line; BLS, Bare Lymphocyte Syndrome; IBD, inflammatory bowel disease; IEC, intestinal epithelial cell; Ii, invariant chain; mcf, mean channel fluorescence; RT-PCR, reverse transcriptase-PCR; TT, tetanus toxoid. 
antigen concentrations. Without $\gamma$-IFN, less efficient antigen presentation, which required a higher concentration of antigen and was not sensitive to leupeptin, was observed. These data suggest that IECs use two distinct pathways for class II-mediated antigen presentation to $\mathrm{CD}^{+} \mathrm{T}$ lymphocytes, and that the relative use of these respective pathways will vary depending on the degree of mucosal inflammation.

\section{Methods}

Cell lines and human IEC. The human colon carcinoma cell lines T84 and HT-29 and SW620 were obtained from the American Type Culture Collection (Rockville, MD). T84, SW620, and the fibroblast retrovirus-producing lines PE-501 and PG-13 were grown in DME supplemented with $10 \% \mathrm{vol} / \mathrm{vol}$ FBS (Hyclone, Logan, UT), $20 \mathrm{mM}$ supplemental glutamine, nonessential amino acids, and penicillin/ streptomycin. HT-29 cells were grown under undifferentiated conditions in McCoy's medium supplemented as above. The B lymphocyte cell line (B-LCL) Priess (homozygous for HLA-DRB1*0401), the HLA class II and HLA-DM $\alpha \beta$ negative Bare Lymphocyte Syndrome (BLS)-1 cell line transfected with HLA-DRB1*0401 (17), the B-LCL MAT, and the T2 cell line containing a HLA class II homozygous deletion were grown in RPMI with $10 \%$ vol/vol FBS. The HLADRB1*0401 restricted $\mathrm{T}$ cell hybridoma cell lines described below were passaged twice weekly in RPMI with $10 \% \mathrm{vol} / \mathrm{vol} \mathrm{FBS}$ and $50 \mu \mathrm{M}$ $\beta$-mercaptoethanol.

The IEC lines were HLA-DR and HLA-DQ genotyped by reverse dot blot hybridization (18). The following HLA haplotypes were identified: T84 (DRB1*0101/09012, DRB4*0101, DQA*0101/ 0501, DQB*03/0303), and HT-29 (DRB $1 * 0402 / 0701$, DRB4*0101, DQA*03/0201, DQB*0302/0201).

Human IEC were prepared from surgical specimens essentially as described (19-21). Each preparation of cells was stained with various $\mathrm{mAb}$, analyzed by flow cytometry, and found to be $<2 \% \mathrm{CD}^{+}$and $>95 \% \mathrm{~B}^{+}$(an IEC specific mAb, kindly provided by L. Mayer, Mount Sinai Medical Center, New York). Chloroquine, bafilomycin $\mathrm{A}_{1}$ brefeldin A were obtained from Sigma Chemical Co. (St. Louis, $\mathrm{MO}$ ), leupeptin and pepstatin from Boehringer Mannheim Biochemicals (Indianapolis, IN), hygromycin from Calbiochem Corp. (La Jolla, CA), G418 (Geneticin) from GIBCO BRL (Gaithersburg, MD), $\gamma$-IFN and GM-CSF from Genzyme, Corp. (Cambridge, MA), and $\mathrm{TNF} \alpha$ from R \& D Systems (Minneapolis, MN).

Flow cytometry. Adherent cells were trypsinized and washed one time in cold PBS. Approximately $10^{6}$ live cells were stained with saturating concentrations of monoclonal antibody in PBS with $0.02 \%$ sodium azide and $0.5 \%$ FBS (staining buffer) at $4^{\circ} \mathrm{C}$ for $30 \mathrm{~min}$. Surface expression of HLA-DR was detected with the monoclonal Ab L243 (22). The secondary reagent used to detect surface staining was phycoerythrin-conjugated goat anti-mouse IgG (Jackson ImmunoResearch Labs Inc., West Grove, PA). A nonspecific isotype matched antibody was used in each experiment to determine background staining. Cells were analyzed and sorted on a FACSCAN ${ }^{\mathrm{TM}}$ flow cytometer.

Generation of retroviral transfectants. The HLA-DRA and -DRB containing retroviral vectors used have been described previously $(17,23)$. Briefly the HLA-DRA or -DRB cDNA was expressed under the control of the CMV-IE promoter and the cDNA for the dominant selectable marker (hygromycin-resistance for the DRA vector and neomycin-resistance for the DRB vectors) was expressed under the control of the viral LTR. $10^{6}$ epithelial cells were plated $24 \mathrm{~h}$ before infection. The cells were washed once, then $3-4 \mathrm{ml}$ of fresh, $0.45 \mu \mathrm{l}$ filtered, viral supernatent supplemented with $4 \mu \mathrm{g} / \mathrm{ml}$ polybrene were added to the adherent cells. After $\sim 8 \mathrm{~h}, 5 \mathrm{ml}$ of fresh complete medium was added and the cells were cultured for $48 \mathrm{~h}$ before drug selection. The cells were first infected with the DRA vector, selected as pools and then infected with the DRB vectors. For HT-29 cells, after the second infection, clones resistant to hygromycin and neomycin were identified, isolated using standard glass cloning rings and expanded and analyzed as clones. T84 cells were resistant to cloning and pools of hygromycin and neomycin resistant T84 cells were expanded and analyzed.

Immunoblotting and analysis of HLA class II dimers. The antibodies used in these studies were: anti-Ii, Pin-1, and anti-HLA-DM $\beta$ rabbit serum (24) (both kindly provided by Dr. Peter Cresswell, Yale University, New Haven, CT); anti-HLA-DM $\alpha$ rabbit serum derived after immunization of rabbits with a peptide (amino acids 73-95) derived from HLA-DM $\alpha$; anti-HLA-DR $\alpha$, DA6.147 (kindly provided by Dr. Veronica Van Heyningen, MRC Human Genetics Unit, Western General Hospital, Edinburgh, United Kingdom).

Cells were trypsinized, as necessary, and washed once with PBS at $4^{\circ} \mathrm{C}$. The cells were then lysed at $5 \times 10^{7} / \mathrm{ml}$ in lysis buffer $(1 \% \mathrm{NP}-40$, $0.15 \mathrm{M} \mathrm{NaCl}, 5 \mathrm{mM}$ EDTA, $50 \mathrm{mM}$ Tris-Cl, pH 7.2, $1.0 \mathrm{mM}$ PMSF, $1.0 \mu \mathrm{g} / \mathrm{ml}$ leupeptin, and $1.0 \mu \mathrm{g} / \mathrm{ml}$ pepstatin) for $30 \mathrm{~min}$ on ice; protease inhibitors were obtained from Boehringer Mannheim Biochemicals. $5-10 \times 10^{6}$ cell equivalents of a cleared lysate were mixed with the appropriate volume of $2 \times$ sample buffer $(1 \times$ concentration: 62.5 $\mathrm{mM}$ Tris-Cl, $\mathrm{pH} 6.8,2 \%$ SDS, $10 \%$ glycerol) with $100 \mathrm{mM}$ DTT added fresh. The samples were boiled for $10 \mathrm{~min}$, electrophoresed on a $10 \%$ polyacrylamide gel, transferred to nitrocellulose, and then immunoblotting was performed. Binding of primary antibodies was detected using peroxidase-conjugated $\mathrm{F}\left(\mathrm{ab}^{\prime}\right)_{2}$ goat anti-mouse IgG + IgM (Jackson ImmunoResearch Laboratories, Inc.) and a chemiluminescent substrate for peroxidase, ECL, (Amersham Corp., Arlington Heights, IL) followed by exposure to film.

To detect HLA class II $\alpha \beta$ dimers, $5-10 \times 10^{6}$ cell equivalents were mixed with the appropriate volume of $2 \times$ sample buffer with or without the addition of DTT. The nonreduced samples were incubated at room temperature for $30 \mathrm{~min}$, and the reduced samples were boiled for $10 \mathrm{~min}$ before loading the samples on a $10 \%$ polyacrylamide gel. Immunoblotting with the DA6.147 was performed as outlined above. The DA6.147 mAb detects both HLA-DR $\alpha \beta$ heterodimers and HLA-DR $\alpha$ monomers.

Reverse transcriptase ( $R T)$-PCR analysis. RNA was prepared from cells using the Quickprep Micro ${ }^{\circledR}$ mRNA purification kit (Pharmacia LKB Biotechnology, Inc., Piscataway, NJ) and converted to cDNA using the Superscript ${ }^{\mathrm{TM}}$ preamplification system (GIBCO BRL). Primers used for glyceraldehyde-3-phosphate dehydrogenase (GAPDH) were 5' TGA TGA CAT CAA GAA GGT GGT 3', 5' CAG TGA GGG TCT CTC TCT TCC 3'; for HLA-DMA were 5' ACT TTT CCC AGA ACA CTC GG 3', 5' CTG GAA GCT GAG TCC ATC G 3'; and for HLA-DMB were 5' ACA GCA CCT CAA CCA AAA AGA 3', 5' GGG GTT AAG GCT AAA TGG GA 3'. Reactions were performed using $1.25 \mathrm{U}$ Taq polymerase, and 30 cycles of $1 \mathrm{~min}$ each at 94, 53, and 72 degrees. This resulted in the generation of a 301-bp, a 341-bp, and a 321-bp for GADPH, DMA, and DMB, respectively. Products of the individual reactions were electrophoresed on $2 \%$ agarose gels and stained with ethidium bromide.

Antigen presentation assays. Antigen specific, HLA-DRB $1 * 0401$ restricted $\mathrm{T}$ cell hybridomas were kindly provided by $\mathrm{D}$. Zaller and L.Wicker (Merck Research Labs, Rahway, NJ). The tetanus-specific $\mathrm{T}$ cell hybrid 49.23.2, and the HSA-specific T cell hybrid 17.9 were generated after immunization of a DRA*DRB1*0401 transgenic mouse with tetanus or HSA, respectively (25). Protein antigens used were tetanus toxoid (TT) (either Wyeth Refined Concentrate; Wyeth-Ayerst, Swiftwater, PA, or \#0054-04-2; Connaught, Marietta, PA) or HSA (protease free, \#A4327; Sigma Chemical Co.). Before use, they were extensively dialyzed at $4^{\circ} \mathrm{C}$ against PBS.

For the antigen presentation assays using the adherent epithelial cell lines, the cells were cultured as indicated in the presence of 500 $\mathrm{U} / \mathrm{ml}$ of $\gamma$-IFN for $48 \mathrm{~h}$. Cells were then trypsinized and plated at $40 \times$ $10^{-3}$ cells per well in a flat bottom 96-well plate in the presence of $\gamma$-IFN as indicated, and allowed to adhere overnight. The cells were pulsed with antigen at the indicated concentration for $6 \mathrm{~h}$ at $37^{\circ} \mathrm{C}$ and free antigen was removed. $10^{5} \mathrm{~T}$ cells were then added and cocultured with the epithelial cells for $24 \mathrm{~h}$, after which the supernatent was col- 
lected. For the assays using the B-LCL Priess and the BLS-1 HLADRA, DRB $1 * 0401$ transfectant, the cells were pulsed with antigen in suspension for $6 \mathrm{~h}$ and washed several times. Fixation, where indicated, was performed by washing cells once with PBS and incubation for 10 min with PBS containing $1 \%$ paraformaldehyde followed by two washes in PBS. T cell IL-2 and IL-4 production was determined by survival of the IL-2/IL-4-dependent cell line HT-2 by measuring $\left[{ }^{3} \mathrm{H}\right]$ thymidine incorporation $(1.0 \mu \mathrm{Ci}$ per well). All assays shown were done in triplicate and repeated at least three times with similar results.

For the drug inhibition studies, cell lines were pulsed with the drug for $1 \mathrm{~h}$ before the addition of antigen. The $6 \mathrm{~h}$ incubation with antigen was in the presence of drug, and the cells were washed to remove drug and antigen before addition of the $\mathrm{T}$ cell hybridoma cells. The doses used were determined to be noncytopathic to the epithelial cells by light microscopy.

TT-specific DRB1*0401-restricted human T cell clones were derived as in (26) from PBMC obtained from a DRB1*0401/DRB1* 0101 donor and enriched for $\mathrm{T}$ cells by passage over nylon wool. These cells were stimulated in the presence of $20 \mathrm{U} / \mathrm{ml} \mathrm{IL-2} \mathrm{by} \mathrm{autologous}$ PBMC which had been pulsed with $2 \mu \mathrm{M}$ TT for $4 \mathrm{~h}$ and irradiated. This $\mathrm{T}$ cell culture was restimulated weekly. Clones were obtained by limiting dilution at ratios of $0.3,3$, and 10 cells per well in Terasaki plates performed at the beginning of the third week. These clones were screened for DRB $1 * 0401$ restriction and TT specificity with a panel of B-LCL of known homozygous HLA haplotype. For proliferation assays, the epithelial cells used as APCs were $\gamma$-irradiated with $15,000 \mathrm{rad}$ before plating at $40 \times 10^{3}$ cells per well in 96-well microtiter plates. After allowing the cells to adhere overnight, the APCs were pulsed with TT for $4 \mathrm{~h}$ and washed to remove free antigen. 50,000 human $\mathrm{T}$ cells were then added to each well, and the $\mathrm{T}$ cells and epithelial cells were coincubated for $72 \mathrm{~h}$, with $1.0 \mu \mathrm{Ci}$ per well $\left[{ }^{3} \mathrm{H}\right]$ thymidine present during the last $16 \mathrm{~h}$. The cultures were harvested onto glass fiber filters using an LKB cell harvester and radiolabel incorporation measured by scintillation spectroscopy and recorded as counts per minute. All data points were obtained using triplicate cultures.

Cathepsin analyses. $2-5 \times 10^{7}$ cells were lysed in $20 \mathrm{mM}$ Hepes, $1 \%$ Triton $\mathrm{X}-100, \mathrm{pH} 6.8$, on ice and the nuclei removed by $5 \mathrm{~min}$ centrifugation in the cold at 1,000 rpm. The lysates were assayed for protein using the Bio-rad protein assay reagent (Bio-Rad Laboratories, Richmond, CA) (27) and several dilutions of each cell lysate were tested in the protease assays to ensure the linear nature and reproducibility of enzyme activity measurements. Cathepsins $\mathrm{B}, \mathrm{L}$, and $\mathrm{H}$ were detected using a fluorometric assay with the following substrates: for cathepsin B: ZArg ArgNMec; cathepsin L: ZpheArgNMec; and cathepsin H: Arg-

\section{A}

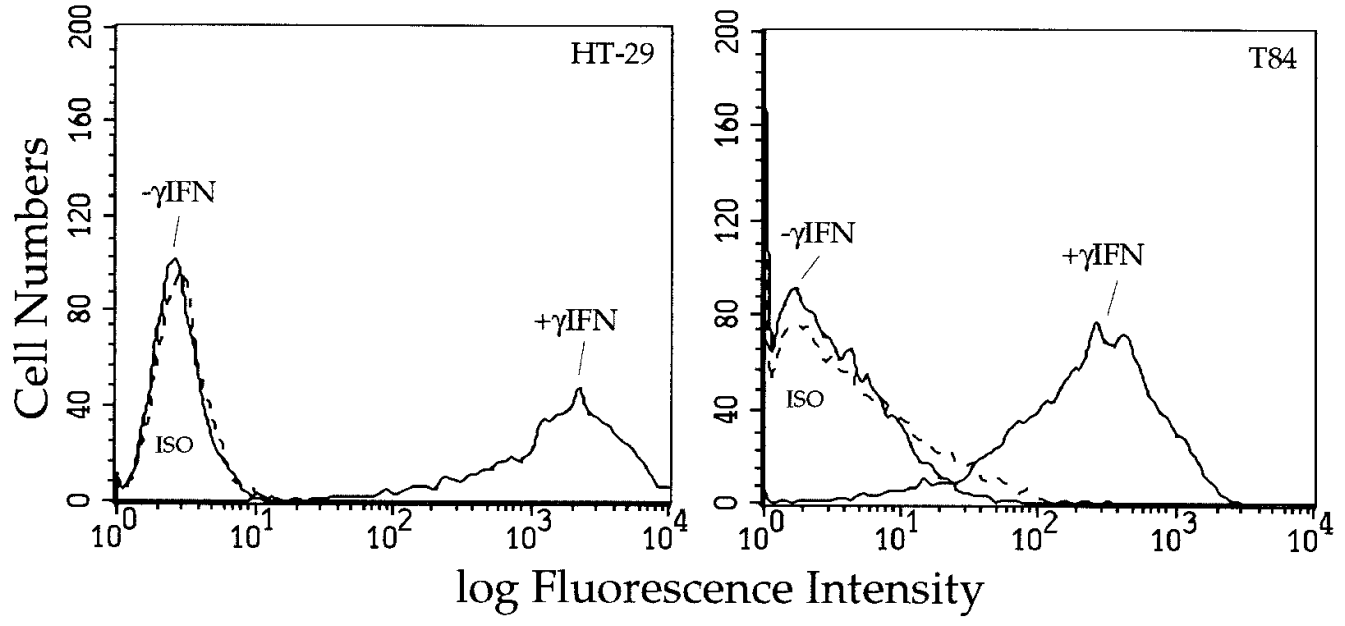

B

Invariant Chain

HLA-DM $\beta$

HLA-DM $\alpha$
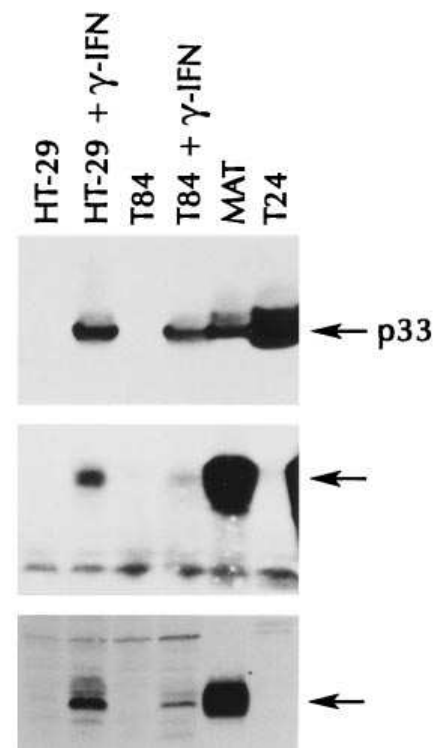

Figure 1. Intestinal epithelial cells express HLA class II molecules, Ii, and HLA$\mathrm{DM} \alpha$ and $\beta$ molecules after stimulation with $\gamma$-IFN. $(A)$ Flow cytometric analysis of surface class II expression in T84 and HT-29. Primary antibody was HLA-DR specific mAb L243. ISO, nonspecific isotype control with identical secondary reagent. The cells were analyzed on a FACSCAN $^{\mathrm{TM}}$ flow cytometer without gating. (B) Immunoblot analysis of Ii, HLA$\mathrm{DM} \beta$, and HLA-DM $\alpha$ in T84 and HT-29. Arrows, 33 $\mathrm{kD}$ core Ii chain, and the predicted MW HLA-DM $\alpha$ and $\beta$ species based upon the mobility of these proteins in the positive control $\mathrm{B}$ cell line MAT. Where indicated, cells were treated with $500 \mathrm{U} / \mathrm{ml} \gamma$-IFN for $48 \mathrm{~h}$ before staining or preparation of the cell lysates. 
$\mathrm{NMec}(28,29)$. Assays were run for $30 \mathrm{~min}$ at $37^{\circ} \mathrm{C}$ in duplicate and enzyme activity calculated as $\mathrm{m}$ units or $\mathrm{n}$ moles product formed per minute. Aspartyl protease activity was measured using 1.6\% hemoglobin as a substrate in $0.2 \mathrm{M}$ sodium acetate, $0.2 \mathrm{M} \mathrm{KCl}, 0.1 \%$ Triton $\mathrm{X}-100, \mathrm{pH} 4.5$, in the presence and absence of $5 \mu \mathrm{g} / \mathrm{ml}$ pepstatin A. These assays were run for $1 \mathrm{~h}$ at $37^{\circ} \mathrm{C}$, followed by precipitation of undigested substrate with trichloroacetic acid and detection of the soluble peptide products with ninhydrin reagent at OD $570 \mathrm{~nm}(30)$. Aspartyl protease activity was calculated such that one unit is equal to the amount of peptide formation inhibitable by pepstatin per microgram cell protein per hour. All assays were repeated twice and the SEM was $<10 \%$.

\section{Results}

$\gamma$-IFN induces HLA class II antigens, Ii, and HLA-DM $\alpha \beta$, and modulates protease activity in IECs. The IEC lines T84 and HT-29 were analyzed by flow cytometry for expression of endogenous HLA-DR molecules on the cell surface before and after stimulation with $\gamma$-IFN. Despite the presence of HLADRA and HLA-DRB message detectable by RT-PCR (HT-29 and T84) and intracellular HLA-DR observed by confocal microscopy (T84) in the absence of cytokine stimulation (data not shown), constitutive surface expression of HLA-DR was not detectable by flow cytometry (Fig. $1 A$ ). Surface expression of HLA-DR molecules was induced by $\gamma$-IFN, with $\sim 50 \%$ maximal surface expression of HLA-DR detected $24 \mathrm{~h}$ after adding $\gamma$-IFN and maximal expression seen after $48 \mathrm{~h}$. HLA-DQ expression was also detected after stimulation with $\gamma$-IFN, but with very different kinetics. Surface expression was not seen until day 7 after stimulation, with maximal levels at day 9 (data not shown).

The Ii and the HLA-DM $\alpha \beta$ heterodimer are required for optimal antigen processing via the HLA class II pathway (for review see references 9 and 10). In general, these molecules are coordinately regulated with HLA-DR expression, although the expression of the HLA class II $\alpha \beta$ heterodimer in the absence of Ii has been reported in IECs (12). However, other investigators have demonstrated the constitutive expression of Ii in IEC in human (31) and mouse (32). We performed Western blots using antibodies specific for Ii, HLA-DM $\alpha$, and HLA-DM $\beta$ to assess whether the epithelial cell lines express these molecules constitutively or after induction with $\gamma$-IFN. For these experiments, we included the T2 cell line (which has a deletion on chromosome 6 that spans the class II region of the MHC including the genes encoding HLA-DM $\alpha$ and $\beta$ ), as a negative control. The expression of the Ii gene (located on human chromosome 5) is unaffected in this mutant cell line. As seen in Fig. $1 B$, no constitutive Ii was detectable in the IEC lines, but the p33 species of Ii was readily inducible in the $\gamma$-IFN treated cells. As seen in Fig. $1 B$, HLA-DM $\alpha$ and $\beta$ protein was detectable only after treatment with $\gamma$-IFN. The expression of both the $\alpha$ and $\beta$ subunits of HLA-DM is required for the accessory role of these proteins in facilitating antigen presentation.

To extend these findings both to normal human IEC and to IBD, we performed RT-PCR using primers specific for either HLA-DMA or -B on cDNA prepared from both intact tissue and purified IEC from normal or inflamed colon tissue. The T2 cell line was used to ensure specificity of the PCR for DMA and DMB. As shown in Fig. 2, expression of HLA-DMA and -B was only seen in the inflamed colon and IEC. Overnight culture of both noninflamed or inflamed IEC in the presence

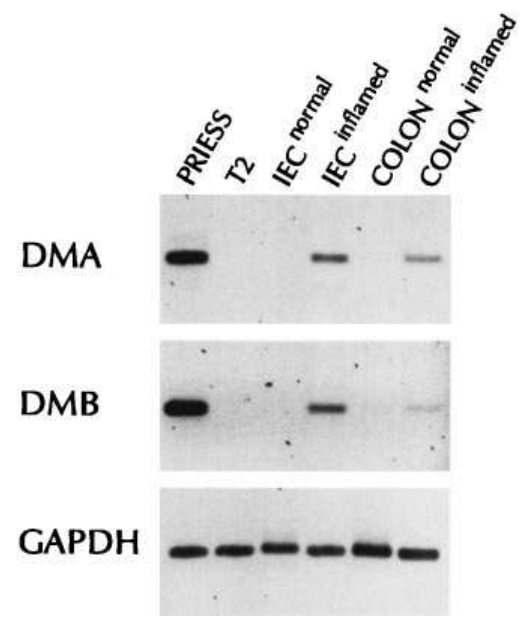

Figure 2. Expression of HLA-DMA and HLADMB in human colon and IEC requires inflammation. RT-PCR analysis of HLA-DMA and $-\mathrm{DMB}$, and GAPDH expression was performed as described in Methods. Normal and inflamed, the histological appearance of the surgical specimen of human colon from which the cDNA was obtained directly or after purification of the epithelial cells. Images were ob-

tained on an Eagle Eye II Imager. Quantitation of band intensity was determined to be in the linear range.

of $\gamma$-IFN resulted in further induction of both HLA-DM genes, without affecting the expression of GAPDH (data not shown).

The expression of cysteine proteases (cathepsins B, L, and $\mathrm{H})$ has been described in the mucosa of the gastrointestinal tract, and these enzymes were histochemically localized to enterocytes of the rat duodenum (33). We performed an analysis of both the cysteine and aspartyl-protease activity in our human IEC lines. The results of the protease assays are shown in Table I, and are representative of three independent assays on each cell line. In all instances, the constitutive activity of cathepsins $\mathrm{B}, \mathrm{L}$, and $\mathrm{H}$, as well as the aspartyl-proteases equaled or exceeded that seen in the human B-LCL Priess. The activity of cathepsin B in the T84 cell line showed a modest (2-3-fold) increase after $\gamma$-IFN stimulation, similar to the increase that is seen in macrophages (Blum, J., unpublished data). Interestingly, the aspartyl-protease activity (and to a lesser extent, the cathepsin $\mathrm{L}$ and $\mathrm{H}$ activity) was lower after $\gamma$-IFN stimulation of T84 cells in each experiment. No significant patterns or changes in protease activity were observed in the HT-29 cell line after stimulation with $\gamma$-IFN.

In the absence of $\gamma$-IFN, expression of a transfected HLA class II allele in IEC lines results in HLA molecules with an altered conformation. To permit the study of the HLA class II molecules and the processing pathway in IECs in the presence or absence of proinflammatory cytokines, we used retroviral gene transfer to constitutively express a specific HLA-DR al-

\section{Table I. Quantitation of Cellular Protease Activity}

\begin{tabular}{lrrrr}
\hline \multicolumn{1}{c}{ Cells } & Cathepsin B* & Cathepsin L* & Cathepsin H* & $\begin{array}{r}\text { Aspartyl } \\
\text { protease }\end{array}$ \\
\hline Priess & $7.57 \times 10^{-2}$ & $1.15 \times 10^{-2}$ & $6.38 \times 10^{-2}$ & $7.5 \times 10^{-6}$ \\
HT-29 & $1.75 \times 10^{-1}$ & $3.20 \times 10^{-1}$ & $2.29 \times 10^{-2}$ & $6.6 \times 10^{-6}$ \\
HT-29+ IFN $\gamma$ & $1.56 \times 10^{-1}$ & $3.92 \times 10^{-1}$ & $2.15 \times 10^{-2}$ & $7.2 \times 10^{-6}$ \\
T84 & $4.73 \times 10^{-1}$ & $7.92 \times 10^{-1}$ & $2.77 \times 10^{-2}$ & $13.5 \times 10^{-6}$ \\
T84 + IFN $\gamma$ & $9.84 \times 10^{-1}$ & $3.22 \times 10^{-1}$ & $1.34 \times 10^{-2}$ & $3.8 \times 10^{-6}$ \\
& & & & \\
\hline
\end{tabular}

* Cathepsins B, L, and H activity are given as milliunits per mg protein.

${ }^{\ddagger}$ Aspartyl protease activity is given as units. 
lele in human IEC lines. Few HLA-DR restricted, antigenspecific $\mathrm{T}$ cell hybridomas have been reported. We had described previously studies using a panel of HLA-DRB1*0401 restricted $\mathrm{T}$ cell hybridomas that were generated in a HLADRB1*0401 transgenic mouse $(22,25)$. As determined by HLA genotyping, neither of the cell lines contained the HLADRB1*0401 allele. Accordingly, we chose the HLA-DRB1*0401 allele for our transfection studies.

The IEC lines were infected with recombinant retroviruses that directed the surface expression of the HLA-DRA/HLADRB1*0401 (DR4) heterodimer. This was accomplished by serial infection first with a retroviral vector expressing the nonpolymorphic DRA allele, followed by infection with a second recombinant virus expressing either the DRB1*0401 allele, or the DRB1*1101 (DR5) allele to be used as a negative control in the processing experiments. As shown in Fig. $3 A$, levels of surface expression similar to that after $\gamma$-IFN induction could be attained in clones (in HT-29) or pools (in T84) of infected cells. In all of the transfectants, we verified the specificity of the expressed HLA-DR using allele specific antibodies (data not shown). The expression seen was stable over 2-3 mo, and fresh aliquots of cells were thawed after every $10-12$ passages for use in the antigen processing studies.

In the absence of HLA-DM $\alpha \beta$, HLA class II antigens display an altered conformation, evidenced by a marked reduction in their ability to form stable $\alpha \beta$ heterodimers in the presence of SDS $(22,34)$. This reflects a relatively inefficient removal of Ii peptides from the peptide binding groove of HLA-DR and a less efficient loading of peptides that would result in a compact form of the HLA-DR $\alpha \beta$ heterodimers that is stable in SDS (35). To determine whether (a) HLA class II antigens differ biochemically when expressed in B lymphocytes as compared to IECs, and $(b)$ Ii and HLA-DM $\alpha \beta$ can alter the conformation of the HLA class II antigens, we looked for SDS-stable HLA class II $\alpha \beta$ heterodimer in the IECs transfected with HLA-DRB1*0401. As a negative control, we used a BLS-1 cell line expressing the same transfected HLA-DRB1*0401 allele. We have shown previously that BLS cells, which do not express HLA-DM $\alpha \beta$ because of a defect in the transcription factor RF-X, do not generate SDS-stable dimers (Fig. $3 B$ and reference 22). Similarly, SDS-stable HLA class II $\alpha \beta$ heterodimers are not observed in either the HT-29 and T84 HLADRB1*0401 transfectants (Fig. $3 B,-\gamma-I F N)$. However, the same transfectants treated with $\gamma$-IFN (resulting in the induction of both Ii and HLA-DM $\alpha \beta$ ) contain SDS-stable dimers. These data suggest that IECs display different MHC-peptide complexes in the presence or absence of inflammatory mediators.

Distinct antigen processing pathways in the epithelial cell HLA class II transfectants in the absence or presence of $\gamma$-IFN. The presence of stable class II dimers only after treatment with $\gamma$-IFN suggested a difference in the processing of class II molecules in the presence or absence of inflammatory cytokines. To determine if these differences were functionally relevant with respect to $\mathrm{T}$ cell stimulation, we then tested the HLADRB1*0401 transfectants for their ability to process and present peptide antigens to T lymphocytes. In the first series of experiments, the responder $\mathrm{T}$ cells were $\mathrm{CD}^{+} \mathrm{T}$ cell hybridomas generated after immunization of HLA-DRB1*0401 transgenic mice with $(a)$ whole TT or $(b)$ HSA (see Methods). The precise HLA-DR restriction of the T cell hybrids to HLA-DRB1* 0401 was confirmed using a large panel of HLA-DR typed

A

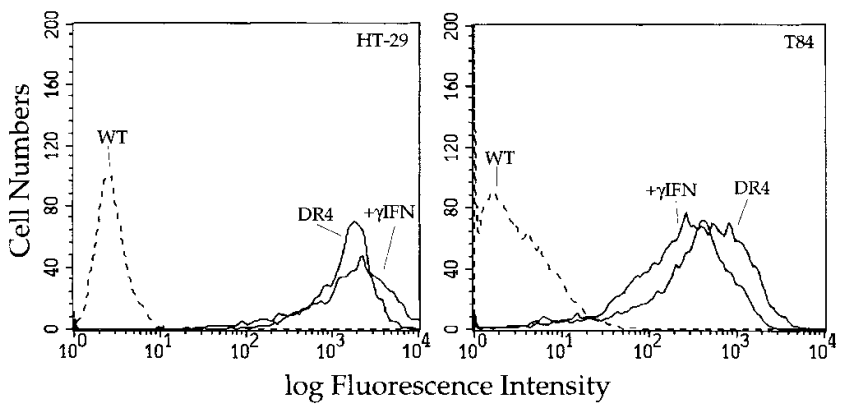

B

HT29 DRADRB $1 * 0401$

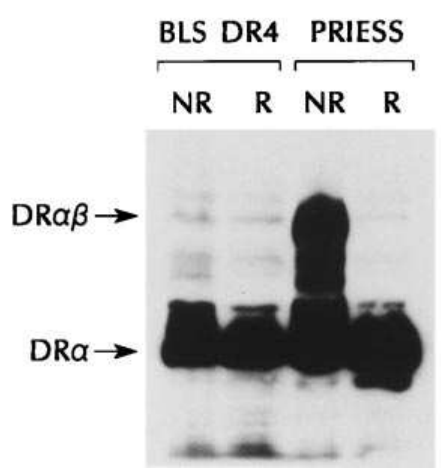

T84 DRADRB $1 * 0401$

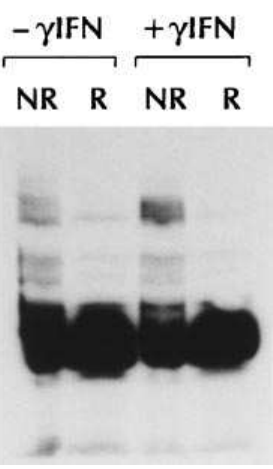

Figure 3. Transfected HLA class II molecules can be expressed at high levels in IEC lines, but are only stable in SDS after treatment with $\gamma$-interferon. $(A)$ Flow cytometric analysis of class II expression using the mAb L243, as in Fig. 1 . DR4 corresponds to the HLA-DRB1*0401 transfectants generated using retroviral vectors without the addition of $\gamma$-IFN. $+\gamma$-IFN corresponds to the wild-type cell treated with $500 \mathrm{U} / \mathrm{ml} \gamma$-IFN for $48 \mathrm{~h}$ before staining. $W T$, the staining of wild-type cells with L243. (B) Detection of SDS stable class II $\alpha \beta$ dimers in the HLA-DRB $1 * 0401$ transfectants by immunoblot analysis using the $\mathrm{mAb}$ DA6.147 which detects both the HLA-DR $\alpha$ monomer and the HLA-DR $\alpha \beta$ dimer. $N R$, the nonreduced, nonboiled lysates prepared in $2 \%$ SDS as outlined in Methods. $R$, identical samples boiled for $10 \mathrm{~min}$ in the presence of DTT. Arrow $D R \alpha \beta$, the $55-60-\mathrm{kD}$ reactivity of the HLA-DR $\alpha \beta$ heterodimer. Arrow $D R \alpha$, the $\sim 30$-kD HLA$\mathrm{DR} \alpha$ monomer. Where indicated, cells were treated with $500 \mathrm{U} / \mathrm{ml} \gamma$-IFN for $48 \mathrm{~h}$ before preparation of the cell lysate. 
A

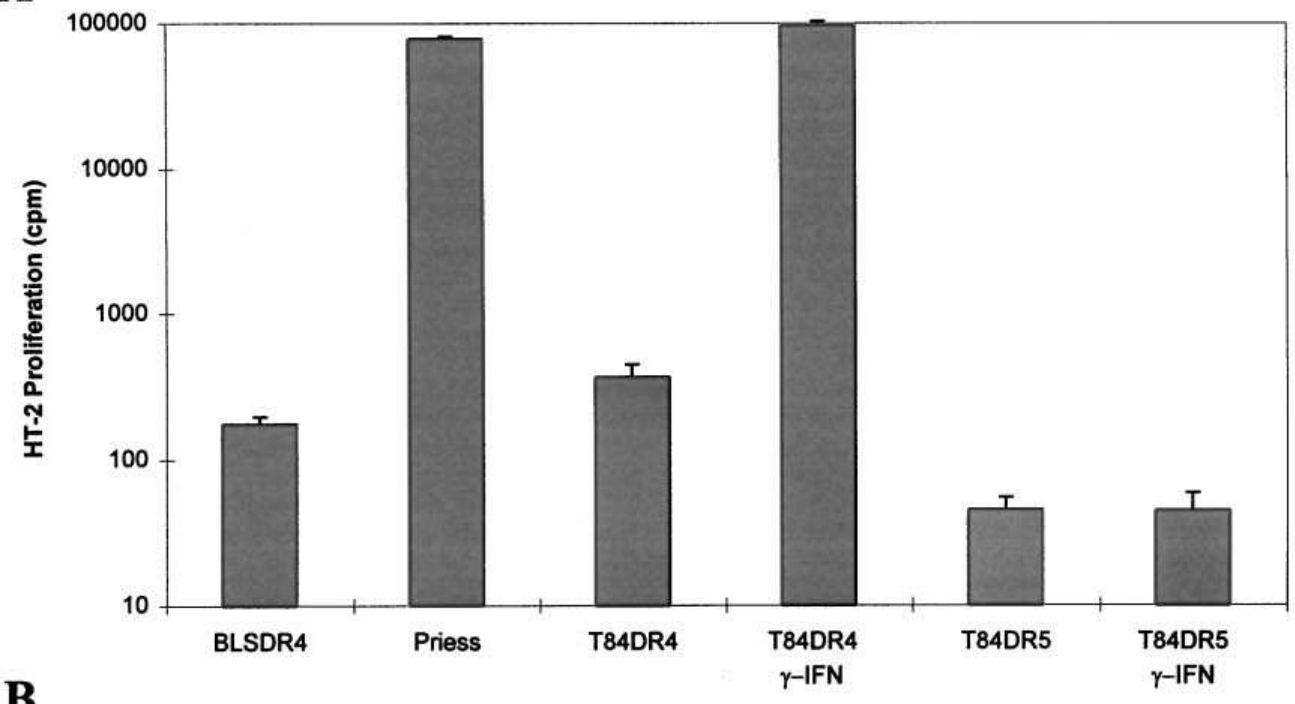

B

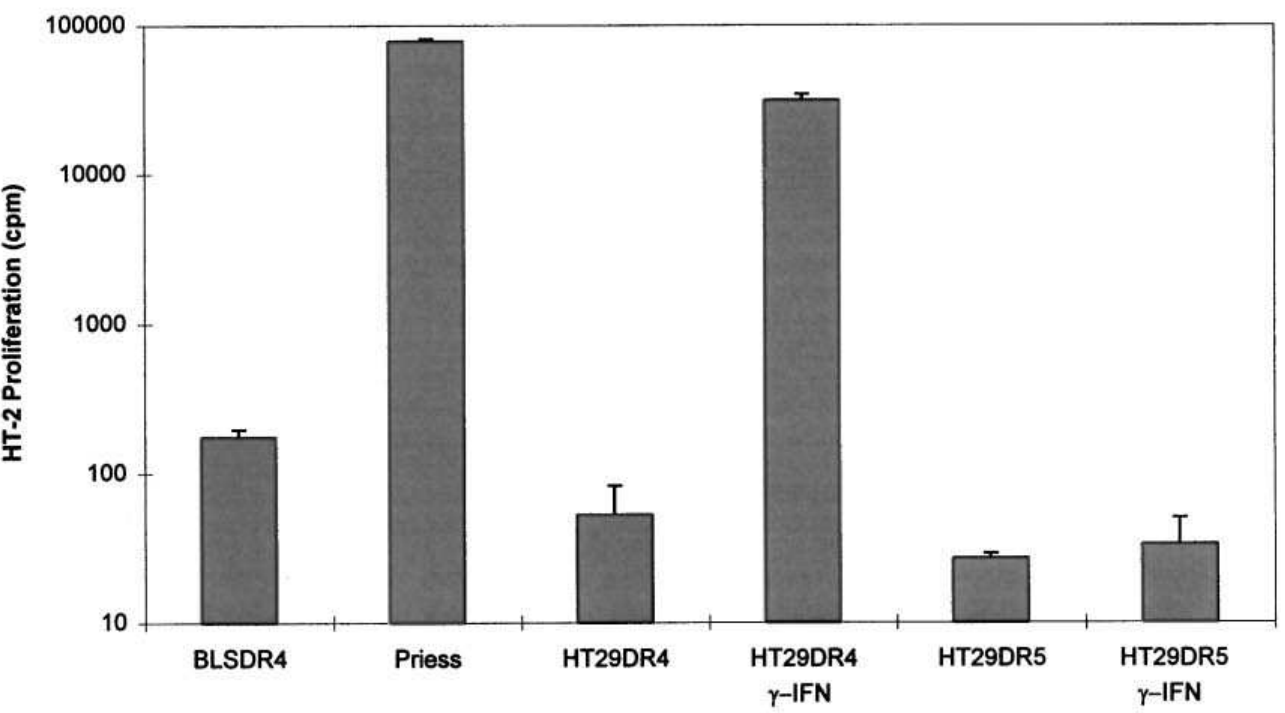

C

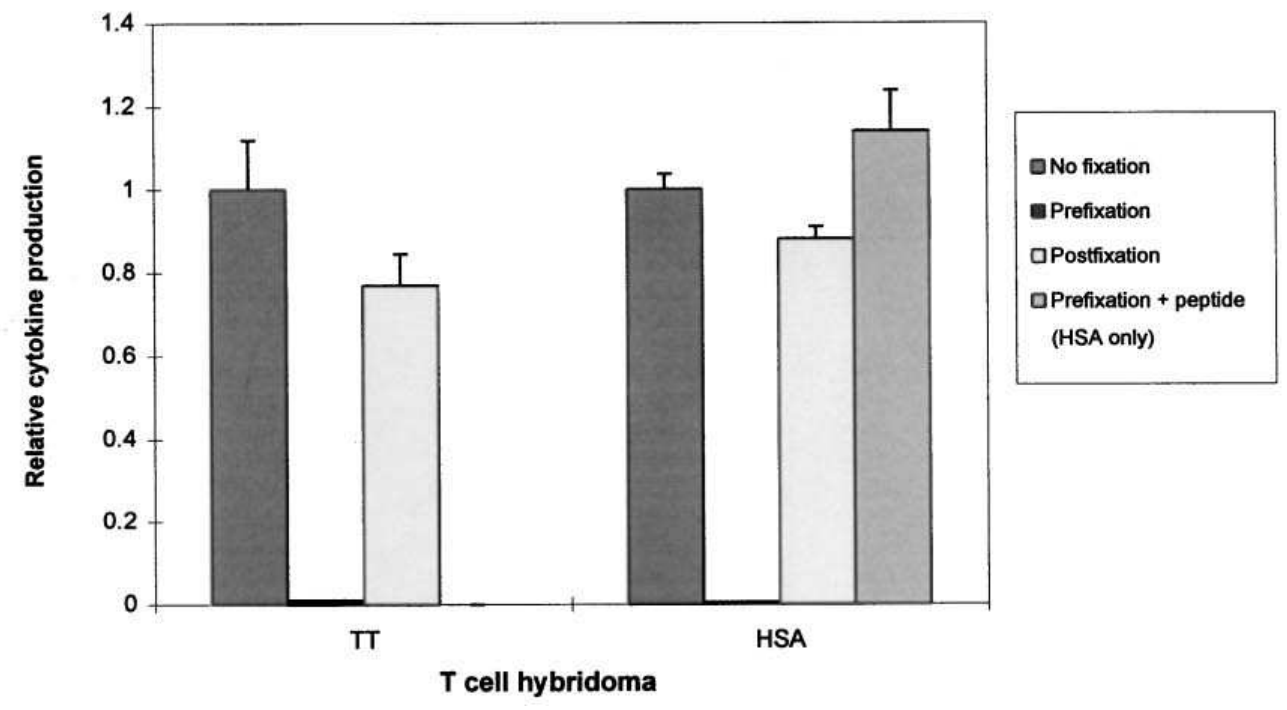

Figure 4. IEC lines transfected with HLA class II alleles can process protein antigens and present peptides to $\mathrm{CD} 4^{+} \mathrm{T}$ cells in an MHC class II restricted manner. Lymphokine production by a TT-specific, HLA-DRB1*0401-restricted $\mathrm{T}$ cell hybridoma after incubation with $(A) \mathrm{T} 84$, or $(B)$ HT-29 cells transfected with either HLA-DRB1*0401 (DR4) or HLA-DRB1*1101

(DR5). Where indicated, IEC lines were stimulated with $\gamma$-IFN at $500 \mathrm{U} / \mathrm{ml}$ for $48 \mathrm{~h}$ before pulsing with antigen. Priess, a B-LCL homozygous for HLA-DRB1*0401.

$B L S D R 4$, BLS cell line transfected with the HLADRB1*0401 allele. (C) Lymphokine production by HLA-DRB1*0401 T cell hybridomas specific for tetanus or HSA after stimulation by T84 HLA-DRB1*0401 transfectants that were fixed with paraformaldehyde before or after pulsing with antigen. Relative $T$ cell stimulation refers to index of counts per minute after fixation divided by the counts per minute obtained with same antigen concentration without fixation. In all cases, the data are presented as proliferation of the IL-2/IL-4-dependent cell line HT-2. The data are mean values from triplicate cultures. Antigen concentrations were $10 \mathrm{uM}$ TT or HSA, or $25 \mathrm{uM}$ of the specific HSA peptide recognized by the HSA hybridoma. 
B-LCLs (data not shown). Epithelial cells transfected with and expressing a HLA-DRB1*1101 (DR5) allele and HLA-DM deficient BLS cells transfected with HLA-DRB1*0401 were used as negative controls in the antigen processing experiments. Fig. $4 A$ shows data from a representative processing experiment using the TT-specific T cell hybridoma. T84 (Fig. $4 A$ ) and HT-29 (Fig. 4 B) HLA-DRB1*0401 transfectants treated with $\gamma$-IFN for $48 \mathrm{~h}$ processed intact TT and presented peptide in an HLA-DR restricted manner. Identical results were obtained using HSA and the HSA-specific T cell hybridoma (data not shown). Maximal values for the T84 transfectants treated with $\gamma$-IFN were consistently as high or higher than the
B-LCL expressing the HLA-DRB1*0401 molecule (Priess). The maximal values seen in the HT-29 transfectants were consistently $20-40 \%$ of those seen in similarly treated T84 transfectants. In no instance was $\mathrm{T}$ cell activation observed within either cell line transfected with HLA-DRB1*1101.

Fixation experiments were performed to formally exclude the possibility that IECs merely were presenting contaminating antigenic peptides rather than processing whole antigen. Epithelial cells were treated with $1 \%$ paraformaldehyde before, or $4 \mathrm{~h}$ after, the addition of antigen. Additionally, with the HSA-specific T cell hybridoma (where the peptide specificity has been determined) peptide was added after prefix-

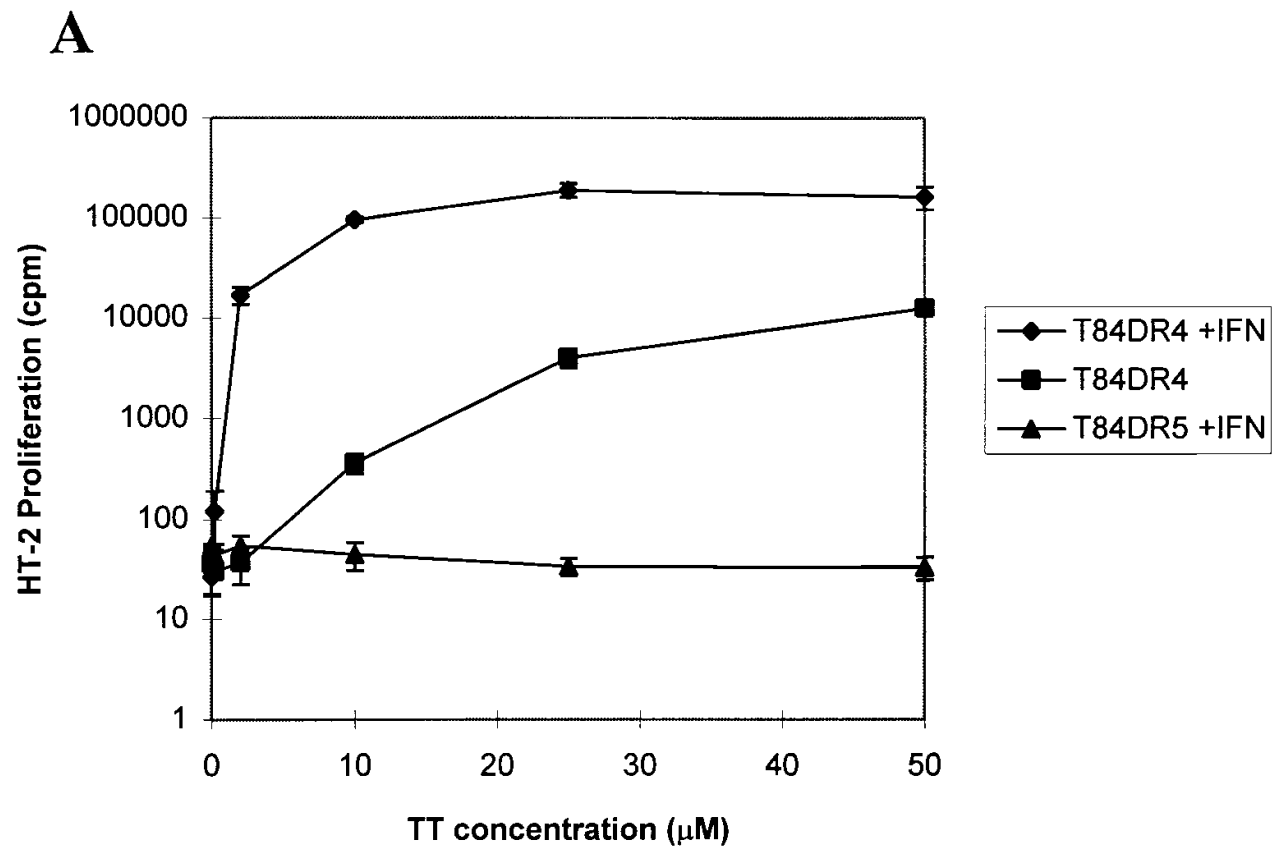

B

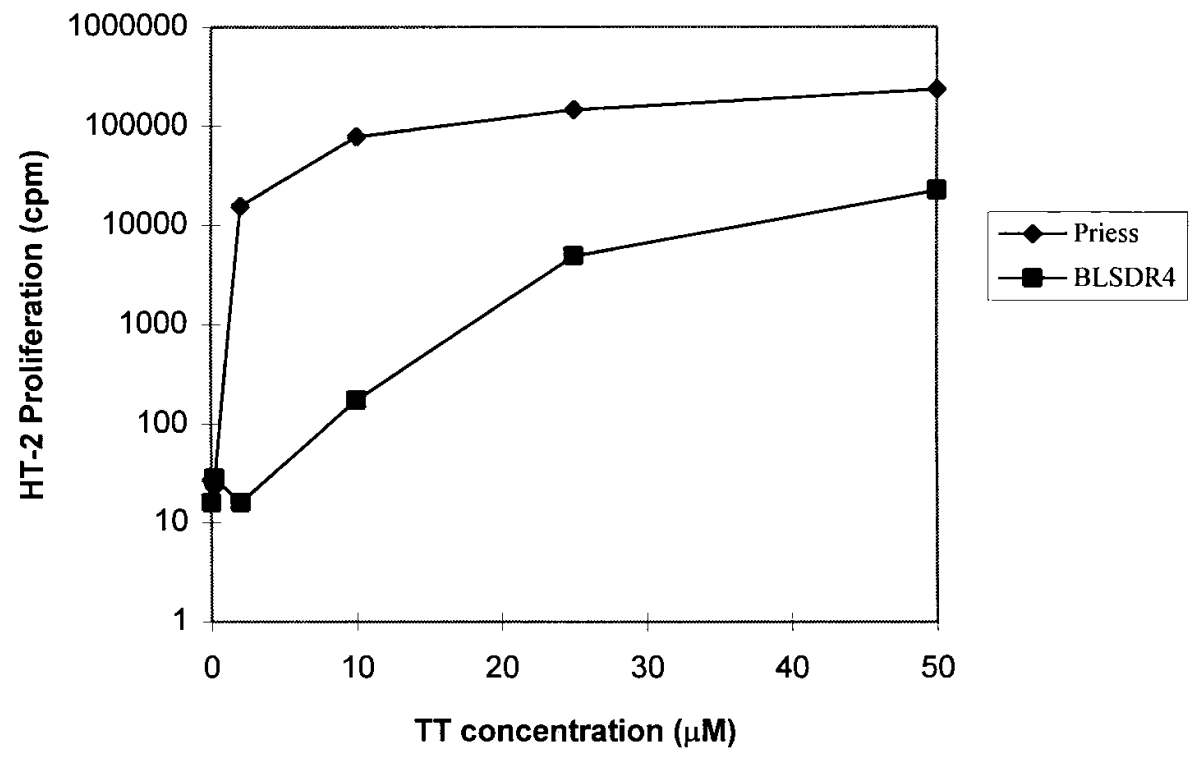

Figure 5. IEC lines can process and present antigen in the absence of $\gamma$-IFN when exposed to antigen at high concentration. $(A)$ TT dose-response curves for the T84 DR4 and DR5 transfectants, in the presence or absence of $\gamma$-IFN $(500 \mathrm{U} / \mathrm{ml})$ as indicated. (B) As in $A$, using Priess and a BLS cell line transfected with HLA-DRB1*0401 as APCs. In both $A$ and $B$, the data presented represent lymphokine production by a HLA-DRB1*0401-restricted $\mathrm{T}$ cell hybridomas specific for TT, assayed using the HT-2 cell line, as described in Fig. 4. 
ation (prefix + peptide). As seen in Fig. $4 C$, prefixation of APC before antigen addition abrogated $T$ cell stimulation. The lack of inhibition in the postfix condition and the complete restoration of the response by adding peptide after prefixation suggest that the effects seen were not the result of the destruction of the HLA class II molecules on the cell during the fixation process. These data (and the drug inhibition data that follow) suggest intracellular processing of antigen is required in these assays to stimulate the T cell hybridomas.

Interestingly, the HLA-DRB1*0401 transfected IEC lines were able to process antigen and stimulate the $T$ cells even in the absence of $\gamma$-IFN when exposed to a relatively high concentration of antigen. The observed processing was dose-dependent (Fig. 5, and similar data with HSA not shown). The responses observed at concentrations above $10 \mu \mathrm{M}$ were $10-20 \%$ of those seen at the same concentration of antigen in the presence of $\gamma$-IFN. The dose response curves comparing antigen processing in the BLS cell line transfected with HLA-DRB1*0401 to the normal B-LCL Priess (homozygous for HLA-DRB1*0401) showed a similar pattern to that seen with the epithelial cell transfectants with and without $\gamma$-IFN (Fig. $5 B$ ).

To investigate whether the antigen presentation observed in the absence of $\gamma$-IFN required high levels of surface class II expression, we sorted the pools of T84 DR4 transfectants using FACS $^{\circledR}$ into high (mean channel fluorescence $\left.[\mathrm{mcf}]=965\right)$, medium $(\mathrm{mcf}=383)$, and low $(\mathrm{mcf}=95)$ fractions and analyzed them independently for their ability to process and present antigen at various antigen concentrations in the absence of $\gamma$-IFN. As seen in Fig. 6, although the difference between the surface class II expression in the high and low fractions is more than 10-fold, only modest differences in processing were seen. It is difficult to directly compare the low expression seen in T84 to the low level of expression seen in normal enterocytes in situ. Still, these data suggest that IEC do not require the extremely high levels of surface class II seen in the context of inflammation to stimulate $\mathrm{CD} 4^{+} \mathrm{T}$ cells. In marked contrast, SW620 cells transfected with the identical HLA-DRB1*0401 allele and expressing this molecule at a high level on its surface were observed to be essentially incapable of processing and presenting antigen (Fig. 6). Hence, overloading any cell line with class II alone is insufficient to confer the ability to process and present antigen to $\mathrm{CD}^{+}{ }^{+} \mathrm{T}$ cells.

Next, we tested several drugs known to block antigen presentation in other systems $(a)$ to determine whether antigen processing by IECs was inhibited in a similar manner to conventional APCs, and $(b)$ to determine whether one could pharmacologically distinguish the $\gamma$-IFN-dependent from the $\gamma$-IFNindependent processing seen in the IEC lines. We compared the response of the drugs in the T84 HLA-DRB1*0401 transfectants with and without $\gamma$-IFN to the response of the HLADRB1*0401 B-LCL Priess. The data are normalized to the T cell stimulation observed in the absence of drug. The transfectants were analyzed by flow cytometry after treatment with the highest concentration of the individual drugs and no decrease
T84DR4 unsorted

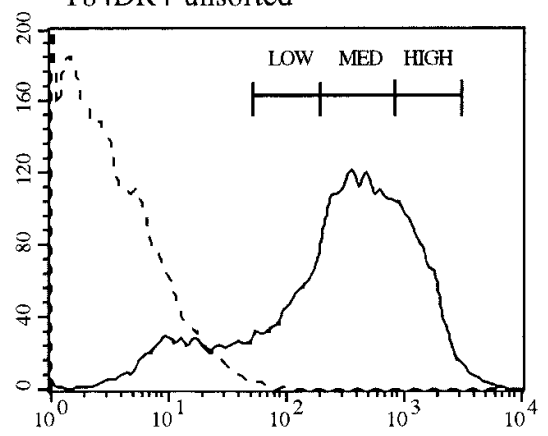

T84DR4 sorted

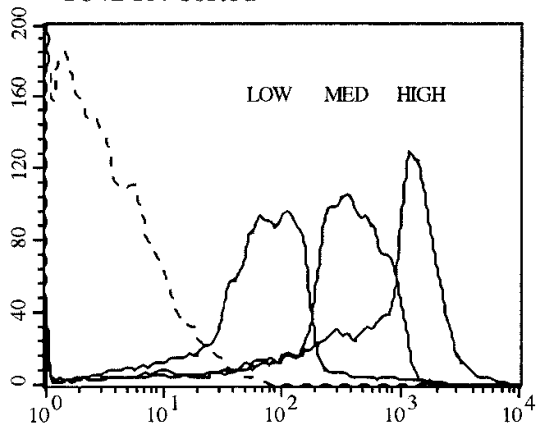

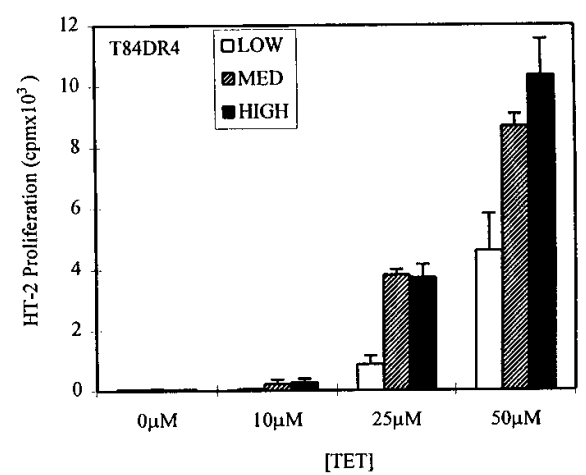

SW620DR4 unsorted
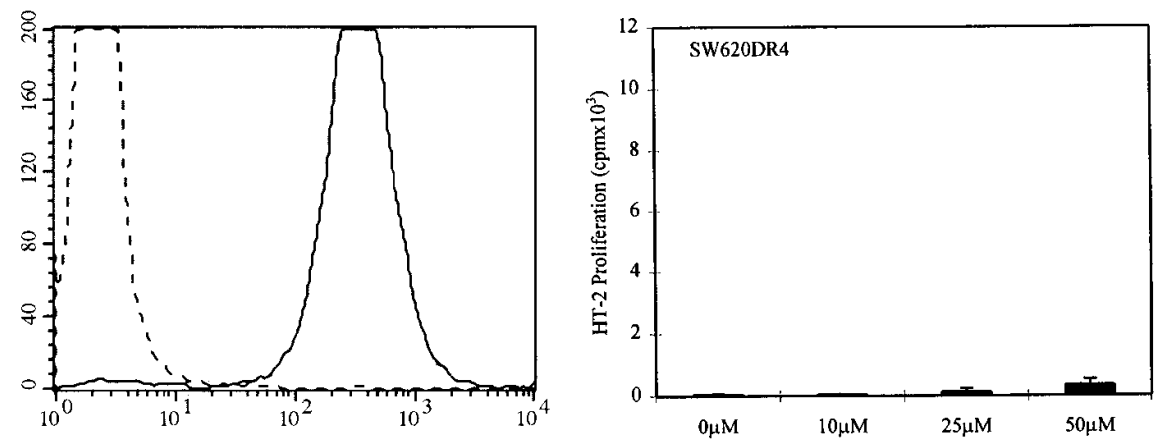

Figure 6. High levels of class II are neither necessary nor sufficient for efficient stimulation of CD4 ${ }^{+}$T cells in the absence of $\gamma$-IFN. T84 HLADRB $1 * 0401$ transfectants, initially selected and expanded as pools, were sorted into high, medium, and low expressing fractions using the mAb L243 and a FACSCAN ${ }^{\mathrm{TM}}$ cell sorter. Mean channel fluorescence of these populations are detailed in the text. The three populations were tested independently for their ability to stimulate the TT-specific, HLA-DRB1*0401-restricted T cell hybridomas after pulsing with various concentrations of TT as in Fig. 4. SW620 HLA-DRB1*0401 transfectants (not sorted) were analyzed in parallel under identical conditions. IL-2 was quantitated as outlined previously. 
in the surface expression of HLA class II molecules was observed (data not shown).

Several distinct patterns were observed. Some drugs, as is seen with chloroquine (Fig. $7 \mathrm{C}$ ), bafilomycin $\mathrm{A}_{1}$ (Fig. $7 \mathrm{D}$ ), and brefeldin $\mathrm{A}$ (not shown), inhibited the antigen processing by the B-LCL, as well as the T84 HLA-DRB1*0401 transfectants with or without stimulation by $\gamma$-IFN. Interestingly, leupeptin consistently inhibited the antigen processing seen in $\mathrm{B}$ cells and in the $\gamma$-IFN treated epithelial cell transfectants, but showed no inhibition of the $\gamma$-IFN-independent processing and presentation (Fig. $7 \mathrm{~B}$ ). Conversely, pepstatin modestly stimulated the $\gamma$-IFN-independent antigen processing in the epithelial transfectants, but not that seen in the B-LCL- or $\gamma$-IFN-treated epithelial cell transfectants (Fig. $7 A$ ). These data suggest that the intrinsic HLA-DM and Ii independent pathway in the epithelial cells differs biochemically from the antigen processing seen in the presence of inflammatory mediators.

IEC HLA-DR transfectants stimulated the proliferation of normal human $C D 4^{+} T$ cell clones. To extend our observations on the $\mathrm{T}$ cell hybridomas, we investigated whether the epithelial cell transfectants could stimulate the antigen-specific, HLA-DR-restricted proliferation of human T cell clones. TT-specific, HLA-DRB1*0401-restricted human T cell clones were generated and tested in antigen processing assays using IECs as APCs. As shown in Fig. $8 A, \gamma$-IFN-stimulated T84 HLA-DRB1*0401 cells pulsed with TT were capable of stimulating the proliferation of two independent $\mathrm{T}$ cell clones in an antigen-specific and HLA-DR-restricted manner.

CD80 and CD86 were not expressed in any of the epithelial cell lines tested and were not induced by $\gamma$-IFN alone or in combination with GM-CSF or TNF $\alpha$ (data not shown).

\section{Discussion}

IECs express a low level of HLA class II antigens constitutively, and their expression is enhanced in inflammatory conditions including IBD (1). In this study, we describe two distinct pathways for antigen processing by IECs that distinguish between the activated and nonactivated states. One pathway is similar to that seen in conventional APCs, uses similar proteases, Ii, HLA-DM $\alpha \beta$, and facilitates efficient antigen presentation even at low antigen concentrations. The other pathway functions independent of Ii and HLA-DM $\alpha \beta$, and requires a relatively high concentration of antigen to elicit $\mathrm{T}$ cell stimulation.

The $\gamma$-IFN stimulated IEC lines express SDS-stable HLADR $\alpha \beta$ heterodimers, Ii, HLA-DM $\alpha \beta$, and contain sufficient protease activity to efficiently process and present exogenous protein antigens to $\mathrm{CD}^{+} \mathrm{T}$ cells. The observation is unlikely to be unique to the IEC lines as enterocytes from inflamed colon (in contrast to those from uninflamed specimens) were also shown to express HLA-DMA and -B, and the expression could be augmented further with exogenous $\gamma$-IFN. In our experiments, the $\gamma$-IFN-dependent antigen processing seen in the T84 cell line was inhibited by chloroquine, bafilomycin, and leupeptin, suggesting the use of an acidic cellular compartment and cysteine proteases in class II processing. In fact, the $\gamma$-IFN stimulated T84 cells were as effective in stimulating the $\mathrm{T}$ cell hybridomas as a $\mathrm{B}-\mathrm{LCL}$ over a wide range of antigen concentrations. These data suggest that in the context of mucosal inflammation, IECs use the conventional class II processing pathway and can function as efficient APCs to $\mathrm{CD} 4^{+}$ $\mathrm{T}$ cells in the lamina propria. $\gamma$-IFN also effects epithelial barrier function and facilitates paracellular transport of luminal
A

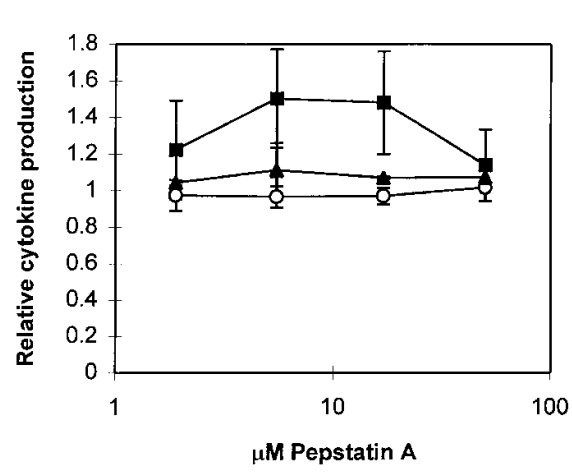

C

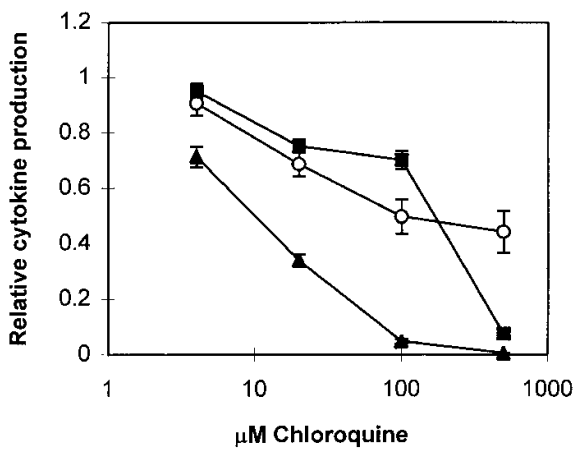

B

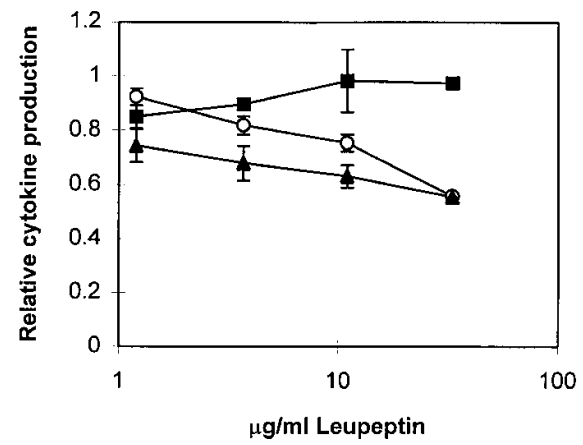

D

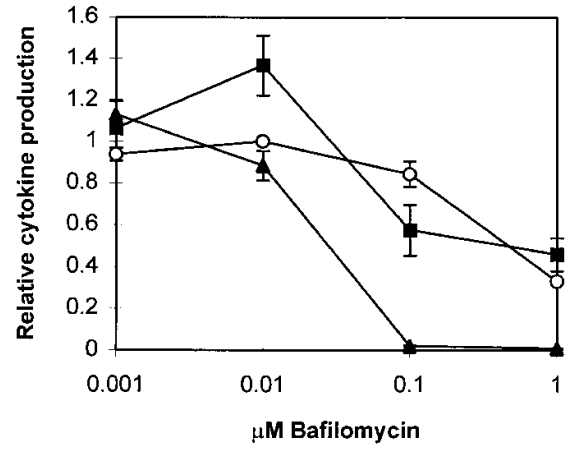

Figure 7. Drug sensitivity of antigen presentation by intestinal epithelial cells. Antigen processing and presentation assays using the HLA-DRB1*0401 T cell hybridomas specific for TT were performed in the presence of various concentrations of pepstatin $(A)$, leupeptin $(B)$, chloroquine $(C)$, and bafilomycin $(D)$. All data were obtained using $10 \mu \mathrm{M} \mathrm{TT}$, and, where indicated, $500 \mathrm{U} / \mathrm{ml}$ of $\gamma$-IFN. Relative T cell stimulation is an index that normalizes the counts per minute at a specific drug concentration to the counts per minute in the absence of any drug, for each cell line. Lymphokine production by the hybridoma was assayed using the HT-2 cell line,

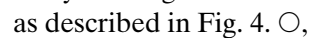
T84DR4 + IFN; $\mathbf{\square , ~ T 8 4 D R 4 ; ~} \boldsymbol{\Delta}$, Priess. 


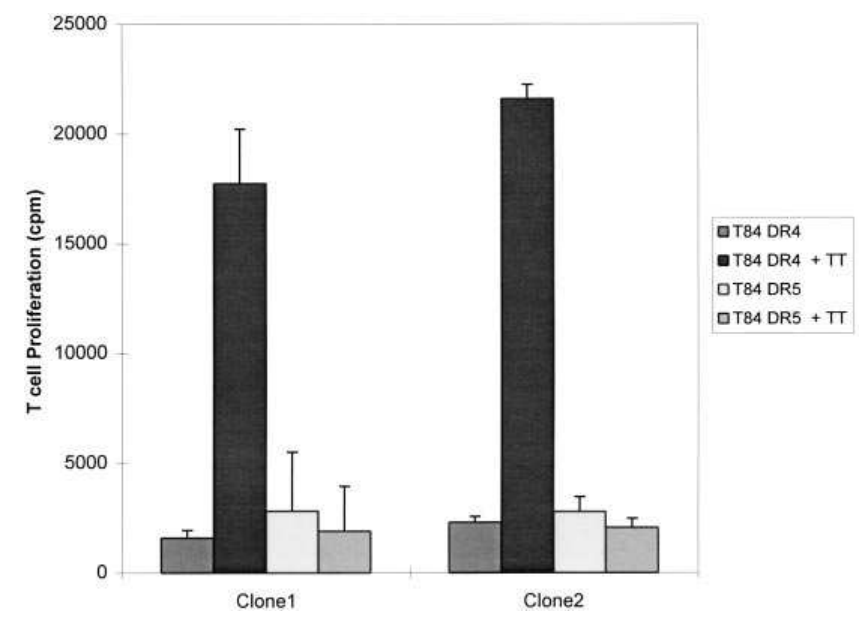

Figure 8. Stimulation of human $\mathrm{CD} 4{ }^{+} \mathrm{T}$ cell clones by intestinal epithelial cells. $\gamma$-IFN-stimulated, $\gamma$-irradiated T84 HLA-DRB1 $* 0401$ (DR4) or HLADRB1*1101 (DR5) transfectants were used to restimulate HLA-DRB1*0401-restricted, TT-specific T cell clones. Data presented are $\left[{ }^{3} \mathrm{H}\right]$ thymidine incorporation by the $\mathrm{T}$ cell clones after a $72 \mathrm{~h}$ coincubation with IEC first pulsed with $10 \mu \mathrm{M}$ TT for $4 \mathrm{~h}$. Data shown are mean values from triplicate cultures using two independently derived clones: Clone 1 and Clone 2.

antigens (36). Hence, both the basolateral and apical surfaces of the enterocyte would be exposed to high concentrations of antigen and could participate in the endocytosis of foreign antigens to initiate processing via class II molecules.

We also demonstrated that IEC lines possess a functional class II pathway that operates in the absence of $\gamma$-IFN (and therefore in the absence of Ii and HLA-DM) and requires a relatively high concentration of antigen. The presentation of exogenous foreign antigens by an APC requires the endocytosis, proteolysis, and loading of the processed peptides onto newly synthesized HLA class II $\alpha \beta$ heterodimers. Ii, encoded by a non-MHC-linked gene, physically associates with nascent HLA class II molecules in the endoplasmic reticulum and directs the complex to an acidic intracellular compartment where peptide loading occurs (for review see reference 9). The products of the MHC-linked HLA-DM $\alpha$ and $\beta$ genes facilitate the removal of residual portion (CLIP) of the Ii from the peptide binding groove of the HLA class II molecules and its replacement with an antigenic peptide. Without the leucine-based endocytic targeting of the newly synthesized class II molecules normally provided by the cytoplasmic tail of Ii (37), or cytoplasmic tail of the HLA-DRA (38) or -DRB chain $(38,39)$, the mechanism of antigen presentation is likely to involve the recycling of class II molecules from the surface to an endocytic compartment where loading of endocytosed, partially degraded peptides can occur. The $\gamma$-IFN-independent pathway in IEC is inhibited by bafilomycin, a specific inhibitor of vacuolar $\left[\mathrm{H}^{+}\right]$ATPase activity $(40,41)$, suggesting the involvement of an acidic late endosomal or lysosomal cellular compartment where degradation of internalized protein antigen would occur. Our data from the BLS HLA-DR transfectants, and data from several groups demonstrating Ii-independent antigen processing indicate that this pathway is not specific to IECs and is likely to be peptide epitope specific $(39,42$; for review see reference 43). However, this pathway may be especially relevant to the physiology of the IEC for two reasons. First, IECs are constantly exposed on their apical surface to the highest concentration of foreign antigen in the body and therefore may sample and present antigens even in the absence of inflammation. Second, unlike conventional APCs, a subset of IECs may normally express class II antigens in the absence HLA-DM (and possibly Ii). Several recent reports have underscored the importance of HLA-DM in editing the peptides that are presented by class II molecules (44). Hence, the HLADM-independent pathway would be likely to result in the processing and loading of peptide epitopes that differ from those seen in the context of mucosal inflammation.

The inhibitor studies point to a important distinction between the two processing pathways. Intracellular protease activity is required both for the proteolytic degradation of endocytosed proteins to antigenic peptides, and for the normal processing of the HLA class II/Ii complex to an intermediate that is a substrate for the HLA-DM $\alpha \beta$ heterodimer. In contrast to the $\gamma$-IFN-stimulated cells and the B-LCL, the antigen processing seen in the untreated HLA-DR transfectants was not inhibited by the cysteine protease inhibitor leupeptin. These data suggest that this pathway is less dependent on the cathepsin proteases B, D, and L that are normally implicated in class II antigen processing (45-47) and are consistent with the lack of requirement for Ii in this pathway. Interestingly, only the $\gamma$-IFN-independent processing was modestly stimulated by the aspartyl protease inhibitor pepstatin. This correlates with the decreased aspartyl protease activity and the enhanced processing seen in the T84 transfectants stimulated with $\gamma$-IFN. Moreover, these findings are consistent with the observations of Vidard et al., which detailed the enhancement of antigen processing and presentation of certain peptide epitopes of ovalbumin after treatment of APCs with protease inhibitors (48). Hence, an important aspect to the regulation of antigen processing in tissues such as epithelia that are rich in aspartyl-proteases may also involve the specific downregulation of protease activity to prevent the degradation of protein antigens to peptide fragments too short to serve as peptide ligands for HLA-DR mediated antigen presentation.

The early reports describing antigen presentation by IECs in human (14) and rat (15) reported the proliferation of CD8 ${ }^{+}$ $\mathrm{T}$ lymphocytes with suppressor activity after stimulation of primed $\mathrm{T}$ cells with antigen pulsed, class II expressing IECs. However, HLA class II molecules are unlikely to stimulate $\mathrm{CD}^{+} \mathrm{T}$ cell responses. Indeed, recent data in humans suggest that the HLA class I like CD1d molecule, which is expressed on IECs (49) is involved in the stimulation of $\mathrm{CD}^{+} \mathrm{T}$ cells in the mucosa (50; for review see reference 51). Subsequent studies suggested that rat enterocytes were unable to efficiently process protein antigens when compared to conventional APCs, and that antigen presentation by IECs was not sensitive to leupeptin (52). These findings are consistent with the leupeptin independence and relatively inefficient processing we observed in the IEC transfectants not treated with $\gamma$-IFN. Parallel studies in murine systems are somewhat conflicting. Kaiserlian et al. have demonstrated efficient class II restricted processing and presentation of antigen to $\mathrm{CD} 4^{+} \mathrm{T}$ cell hybridomas using purified murine villous IECs (16). Hoyne et al. subsequently described the inability of murine IECs to process protein antigens, despite their ability to present peptides to T cells (53). Whether differences in the protocols used to isolate the IECs and/or differences in baseline levels of intestinal inflammation 
can reconcile these differences remains to be seen. In this regard, variability in class II expression is observed along both the crypt-villous (1) and rostral-caudal (54) axes, probably underscoring important regional distinctions in the ability of the intestinal epithelium to process and present antigen to T cells.

In summary, IECs have extensive contact with $\mathrm{T}$ lymphocytes both within the epithelium and in the underlying lamina propria (55). IECs are capable of expressing HLA class II molecules in a variety of immunopathological contexts characterized by mucosal inflammation with the associated production of inflammatory cytokines. In the presence of $\gamma$-IFN, IECs become competent, efficient APCs, and are likely to contribute to the stimulation of $\mathrm{CD}^{+}{ }^{+} \mathrm{T}$ cells that accumulate in the intestinal mucosa. In the absence of $\gamma$-IFN, IECs can use a distinct class II pathway that requires higher concentrations of antigen and functions in the absence of HLA-DM. The polarized morphology of IECs underscores the functional segregation between apical and basolateral events. It is possible that the $\gamma$-IFN-dependent and -independent pathways will correspond to antigen processing after endocytosis from the apical and basolateral surface, respectively. In addition, oral tolerance to fed antigens, which does not occur in mice after administration of $\gamma$-IFN (56), may be associated with the selective use of the nonconventional class II pathway in enterocytes.

\section{Acknowledgments}

We gratefully acknowledge Dr. William Kwok for providing help with retroviral infections; Dr. Linda Wicker and Dennis Zaller (Merck Research Labs) for assistance with the T cell hybridomas; Susan Masewicz for help in establishing the human T cell clones; Dr. Allan Mowat for helpful discussions and critical review of the manuscript; and Holly Chase for assistance in preparing the manuscript. R.M. Hershberg would like to dedicate this manuscript to Dr. John A. Ryan, Jr.

The work was supported from the Virginia Mason Medical Center Department of Surgery (R.M. Hershberg), by grant \#AI38913 from the NIH (G.T. Nepom), a National Research Service Award from NIH (S. Kovats), and grant \#AI33418 and \#DK94017 from the NIH (J.S. Blum).

\section{References}

1. Mayer, L., D. Eisenhardt, P. Salomon, W. Bauer, R. Plous, and L. Piccinini. 1991. Expression of class II molecules on intestinal epithelial cells in humans. Differences between normal and inflammatory bowel disease. Gastroenterology. 100:3-12.

2. Bland, P.W., and C.V. Whiting. 1992. Induction of MHC class II gene products in rat intestinal epithelium during graft-versus-host disease and effects on the immune function of the epithelium. Immunology. 75:366-371.

3. Ciclitira, P.J., J.M. Nelufer, H.J. Ellis, and D.J. Evans. 1986. The effect of gluten on HLA-DR in the small intestinal epithelium of patients with Coeliac disease. Clin. Exp. Immunol. 63:101-104.

4. Germain, R.N. 1994. MHC-dependent antigen processing and peptide presentation: providing ligands for T lymphocyte activation. Cell. 76:287-299.

5. Powrie, F. 1995. T cells in inflammatory bowel disease: protective and pathogenic roles. Immunity. 3:171-174.

6. Chen, Y., J. Inobe, and H.L. Weiner. 1995. Induction of oral tolerance to myelin basic protein in CD8-depleted mice: both CD4+ and CD8+ cells mediate active suppression. J. Immunol. 155:910-916.

7. Garside, P., M. Steel, F.Y. Liew, and A.M. Mowat. 1995. CD4+ but not $\mathrm{CD} 8+\mathrm{T}$ cells are required for the induction of oral tolerance. Int. Immunol. 7 : 501-504.

8. Barone, K.S., S.L. Jain, and J.G. Michael. 1995. Effect of in vivo depletion of CD4+ and CD8+ cells on the induction and maintenance of oral tolerance. Cell. Immunol. 163:19-29.

9. Wolf, P.R., and H.L. Ploegh. 1995. How MHC class II molecules acquire peptide cargo: biosynthesis and trafficking through the endocytic pathway. Annu. Rev. Cell Dev. Biol. 267-306.
10. Cresswell, P. 1994. Assembly, transport, and function of MHC class II molecules. Annu. Rev. Immunol. 12:259-293.

11. Chang, C.H., and R.A. Flavell. 1995. Class II transactivator regulates the expression of multiple genes involved in antigen presentation. J. Exp. Med. 181:765-767.

12. Vidal, K., C. Samarut, J.-P. Magaud, J.-P. Revillard, and D. Kaiserlian. 1993. Unexpected lack of reactivity of allogeneic anti-Ia monoclonal antibodies with MHC class II molecules expressed by mouse intestinal epithelial cells. $J$. Immunol. 151:4642-4650.

13. Bland, P.W., and D.M. Kambarage. 1991. Antigen handling by the epithelian and lamina propria macrophages. Gastroenterol. Clin. North Am. 20: 577-596.

14. Mayer, L., and R. Shlien. 1987. Evidence for function of Ia molecules on gut epithelial cells in man. J. Exp. Med. 166:1471-1483.

15. Bland, P.W., and L.G. Warren. 1986. Antigen presentation by epithelial cells of the rat small intestine. I. Kinetics, antigen specificity and blocking by anti-Ia antisera. Immunology. 58:1-7.

16. Kaiserlian, D., K. Vidal, and J.-P. Revillard. 1989. Murine enterocytes can present soluble antigen to specific class II-restricted CD4+ T cells. Eur. J. Immunol. 19:1513-1516.

17. Kovats, S., S. Drover, W. Marshall, D. Freed, P. Whiteley, G.T. Nepom, and J.S. Blum. 1994. Coordinate defects in HLA class II expression and antigen presentation in bare lymphocyte syndrome. J. Exp. Med. 179:2017-2022.

18. Leech, N., W. Hagopian, J.A. Hansen, G.T. Nepom, and A. Kitabchi. 1997. GAD65 and islet cell autoantibodies are associated with HLA class II alleles in Black Americans. Autoimmunity. In press.

19. MacDonald, M.J., J. Gottschall, J.B. Hunter, and K.L. Winter. 1986. HLA-DR4 in insulin-dependent diabetic parents and their diabetic offspring: a clue to dominant inheritance. Proc. Natl. Acad. Sci. USA. 83:7049-7053.

20. Inoko, H., A. Ando, K. Tsuji, K. Matsuki, T. Juji, and Y. Honda. 1986. HLA-DQ beta chain DNA restriction fragments can differentiate between healthy and narcoleptic individuals with HLA-DR2. Immunogenetics. 23:126-128.

21. Cohen-Haguenauer, O., E. Robbins, C. Massart, M. Busson, I. Deschamps, J. Hors, J.M. Lalouel, J. Dausset, and D. Cohen. 1985. A systematic study of HLA class II-beta DNA restriction fragments in insulin-dependent diabetes mellitus. Proc. Natl. Acad. Sci. USA. 82:3335-3339.

22. Kovats, S., G.T. Nepom, M. Coleman, B. Nepom, W.W. Kwok, and J.S Blum. 1995. Deficient antigen presenting cell function in multiple genetic complementation groups of type II bare lymphocyte syndrome. J. Clin. Invest. 96: 217-223.

23. Kwok, W.W., D. Schwarz, B.S. Nepom, P.S. Thurtle, R.A. Hock, and G.T. Nepom. 1988. HLA-DQ molecules form $\alpha-\beta$ heterodimers of mixed allotype. J. Immunol. 141:3123-3127.

24. Denzin, L.K., N.F. Robbins, C. Carboy-Newcomb, and P. Cresswell. 1994. Assembly and intracellular transport of HLA-DM and correction of the class II antigen-processing defect in T2 cells. Immunity. 1:595-606.

25. Woods, A., H.Y. Chen, M.E. Trumbauer, A. Sirotina, R. Cummings, and D.M. Zaller. 1994. Human major histocompatibility complex class IIrestricted T cell responses in transgenic mice. J. Exp. Med. 180:173-181.

26. Tuosto, L., R.W. Karr, X.T. Fu, R.R. Olson, E. Cundari, E. Piccolella, R. Lechler, and G. Lombardi. 1994. Different regions of the N-terminal domains of HLA-DR1 influence recognition of individual peptide-DR1 complexes. Hum. Immunol. 40:312-322.

27. Weiner, G.J., and M.S. Kaminski. 1990. Anti-idiotypic antibodies recognizing stable epitopes limit the emergency of idiotype variants in a murine B cell lymphoma. J. Immunol. 144:2436-2445.

28. Barrett, A.J. 1980. Fluorimetric assays for Cathepsin B and Cathepsin H with methylcoumarylamide substrates. Biochem. J. 187:909-912.

29. Barrett, A.J., and H. Kirschke. 1981. Cathepsin B, Cathepsin H, and Cathepsin L. Methods Enzymol. 80:535-561.

30. Diment, S., M.S. Leech, and P.D. Stahl. 1988. Cathepsin D is membraneassociated in macrophage endosomes. J. Biol. Chem. 263:6901-6907.

31. Momburg, F., K. Koretz, and A. Von Herbay. 1988. Nonimmune human cells can express MHC class II antigens in the absence of invariant chain-an immunohistological study on normal and chronically inflamed small intestine. Clin. Exp. Immunol. 72:367-372.

32. Sanderson, I.R., A.J. Ouellette, E.A. Carter, and P.R. Harmatz. 1992. Ontogeny of class II MHC mRNA in the mouse small intestinal epithelium. Mol. Immunol. 29:1257-1263.

33. Furuhashi, M., A. Nakahara, H. Fukutomi, E. Kominami, D. Grube, and Y. Uchiyama. 1991. Immunocytochemical localization of cathepsins B, H, and $\mathrm{L}$ in the rat gastro-duodenal mucosa. Histochemistry. 95:231-239.

34. Mellins, E., L. Smith, B. Arp, T. Cotner, E. Celis, and D. Pious. 1990 Defective processing and presentation of exogenous antigens in mutants with normal HLA class II genes. Nature (Lond.). 343:71-74.

35. Roche, P.A. 1995. HLA-DM: an in vivo facilitator of MHC class II peptide loading. Immunity. 3:259-262.

36. Madara, J.L., and J. Stafford. 1989. Interferon-gamma directly affects barrier function of cultured intestinal epithelial monolayers. J. Clin. Invest. 83: 724-727.

37. Bakke, O., and B. Dobberstein. 1990. MHC class II-associated invariant chain contains a sorting signal for endosomal compartments. Cell. 63:707-716. 
38. Pinet, V., M. Vergelli, R. Martin, O. Bakke, and E.O. Long. 1995. Antigen presentation mediated by recycling of surface HLA-DR molecules. Nature (Lond.). 375:603-604.

39. Zhong, G., P. Romagnoli, and R.N. Germain. 1997. Related leucinebased cytoplasmic targeting signals in invariant chain and major histocompatibility complex class II molecules control endocytic presentation of distinct determinants in a single protein. J. Exp. Med. 185:429-438.

40. Lencer, W.I., G. Strohmeier, S. Moe, S.L. Carlson, C.T. Constable, and J.L. Madara. 1995. Signal transduction by cholera toxin: processing in vesicular compartments does not require acidification. Am. J. Physiol. 269:G548-G557.

41. Yoshimori, T., A. Yamamoto, Y. Moriyama, M. Futai, and Y. Tashiro. 1991. Bafilomycin $\mathrm{A}_{1}$, a specific inhibitor of vacuolar-type $\mathrm{H}^{+}$-ATPase, inhibits acidification and protein degradation in lysosomes of cultured cells. J. Biol. Chem. 266:17707-17712.

42. Pinet, V., M.S. Malnati, and E.O. Long. 1994. Two processing pathways for the MHC class II-restricted presentation of exogenous influenza virus antigen. J. Immunol. 152:4852-4860.

43. Ceman, S., and A.J. Sant. 1995. The function of invariant chain in class II-restricted antigen presentation. Semin. Immunol. 7:373-387.

44. Katz, J.F., C. Stebbins, E. Appella, and A.J. Sant. 1996. Invariant chain and DM edit self-peptide presentation by major histocompatibility complex (MHC) class II molecules. J. Exp. Med. 184:1747-1753.

45. Buus, S., and O. Werdelin. 1986. A group-specific inhibitor of lysosomal cysteine proteinases selectively inhibits both proteolytic degradation and presentation of the antigen dinitrophenyl-poly-L-lysine by guinea pig accessory cells to T cells. J. Immunol. 136:452-458.

46. Mizuochi, T., S.-T. Yee, M. Kasai, T. Kakiuchi, D. Muno, and E. Kominami. 1994. Both cathepsin B and cathepsin D are necessary for processing of ovalbumin as well as for degradation of class II MHC invariant chain. Immunol.
Let. 43:189-193.

47. Rodriguez, G.M., and S. Diment. 1992. Role of cathepsin D in antigen presentation of ovalbumin. J. Immunol. 149:2894-2898.

48. Vidard, L., K.L. Rock, and B. Benacerraf. 1991. The generation of immunogenic peptides can be selectively increased or decreased by proteolytic enzyme inhibitors. J. Immunol. 147:1786-1791.

49. Blumberg, R.S., C. Terhorst, P. Bleicher, F.V. McDermott, C.H. Allan, S.B. Landau, J.S. Trier, and S.P. Balk. 1991. Expression of a nonpolymorphic MHC class I-like molecule, CD1D, by human intestinal epithelial cells. J. Immunol. 147:2518-2524.

50. Panja, A., A. Barone, and L. Mayer. 1994. Stimulation of lamina propria lymphocytes by intestinal epithelial cells: evidence for recognition of nonclassical restriction elements. J. Exp. Med. 179:943-950.

51. Blumberg, R.S., and S.P. Balk. 1994. Intraepithelial lymphocytes and their recognition of non-classical MHC molecules. Intern. Rev. Immunol. 11:15-30.

52. Bland, P.W., and C.V. Whiting. 1989. Antigen processing by isolated rat intestinal villus enterocytes. Immunology. 68:497-502.

53. Hoyne, G.F., M.G. Callow, M.-C. Kuo, and W.R. Thomas. 1993. Presentation of peptides and proteins by intestinal epithelial cells. Immunology. 80: 204-208.

54. Sidhu, N.K., G.M. Wright, R.J.F. Markham, W.P. Ireland, and A. Singh. 1992. Quantitative regional variation in the expression of major histocompatibility class II antigens in enterocytes of the mouse small intestine. Tissue Cell. 24:221-228.

55. Hashimoto, Y., and T. Komuro. 1988. Close relationships between the cells of the immune system and the epithelial cells in the rat small intestine. Cell Tissue Res. 254:41-47.

56. Zhang, Z., and J.G. Michael. 1990. Orally inducible immune unresponsiveness is abrogated by IFN-gamma treatment. J. Immunol. 144:4163-4165. 